\title{
Marcas de uso e redes medioestruturais de verbetes sobre homossexual masculino em dicionários escolares
}

\section{Labels and mediostructural networks of entries about male homosexuals in school dictionaries}

\author{
Hugo Leonardo Gomes dos Santos* \\ Antônio Luciano Pontes ${ }^{* *}$ \\ Pedro Henrique Lima Praxedes Filho ${ }^{* * *}$
}

\begin{abstract}
RESUMO: Nosso objetivo foi investigar quais as marcas de uso utilizadas nos dicionários escolares tipo 3 do Programa Nacional do Livro Didático 2012 para indicar as restrições e os contextos de uso de palavras relacionadas a homossexual masculino, bem como suas implicações para a compreensão dos sentidos ali expressos. Buscamos fundamentação teórica nos campos da Metalexicografia e da Lexicografia Pedagógica (WELKER, 2004; PONTES, 2009; 2012; GARRIGA ESCRIBANO, 1994; 1995; FAJARDO, 1997) e operamos uma pesquisa descritiva e qualitativa. Apresentamos um levantamento de 11 entradas relacionadas a homossexual masculino, totalizando 44 verbetes extraídos de cinco dicionários escolares. A partir das definições selecionadas, elaboramos redes de fluxo de sentido, redes medioestruturais, e analisamos o posicionamento das marcas de uso empregadas por cada dicionário, nas redes elaboradas, e os padrões de marcação de cada palavra. Em relação às conclusões, podemos destacar dois

ABSTRACT: Our aim was to investigate the use of usage labels in type 3 school dictionaries adopted by the National Program of Textbooks 2012 in order that we could indicate the restrictions and contexts of use of words related to male homosexuals, as well as their implications for the understanding of the senses expressed there. We sought theoretical support in studies within the fields of Metalexicography and Pedagogical Lexicography, such as Welker (2004), Pontes (2009; 2012), Garriga Escribano (1994; 1995), and Fajardo (1997). We conducted a qualitative descriptive study. We presented a survey of 11 word-entries related to male homosexuals, totalizing 44 entries extracted from five school dictionaries. The selected definitions were used for the elaboration of sense-flow networks, mediostructural networks. We then analyzed the location of the usage labels used by each dictionary in the mediostructural network and the labeling patterns for each word. In relation to the conclusions, we can highlight two
\end{abstract}

\footnotetext{
* Mestre em Linguística Aplicada (2016) pela Universidade Estadual do Ceará - UECE. Doutorando em Linguística pela Universidade Federal do Ceará - UFC. prof.hugoleo13@gmail.com.

** Doutor em Letras (1996) pela Universidade Estadual Paulista Júlio de Mesquita Filho - UNESP. Professor da Universidade do Estado do Rio Grande do Norte - UERN. pontes321@hotmail.com.

${ }^{* * * *}$ Doutor em Letras - Inglês (2007) pela Universidade Federal de Santa Catarina - UFSC. Professor da Universidade Estadual do Ceará - UECE. pedro.praxedes@uece.br.
} 
aspectos: (1) a marca mais recorrente em nosso corpus foi a que se refere ao uso pejorativo, indicando os contextos discriminatórios em que essas palavras são empregadas; e (2) palavras marcadas, como "bicha", "baitola" e "maricas", por exemplo, estão posicionadas às margens da rede e o fluxo de sentidos converge dessas palavras para as palavras não marcadas "gay" e "homossexual".

PALAVRAS-CHAVE: Homossexual masculino. Dicionário escolar. Marcas de uso. Pejorativo. aspects: (1) the most recurrent label in our corpus was that referring to derogatory use, indicating the discriminatory contexts in which these words are used; and (2) marked words like "bicha", "baitola" e "maricas", for example, are located at the network periphery and the flow of meanings converges from those words to the unmarked words "gay" and "homosexual".

KEYWORDS: Male homosexual. School dictionary. Usage labels. Derogatory.

\section{Introdução}

As discussões sobre gênero e sexualidade estão cada vez mais ganhando visibilidade na mídia e no meio acadêmico. Os preconceitos relacionados às diversas identificações de gênero e orientações sexuais se manifestam de diferentes formas, desde a violência física e o bullying até a violência psicológica e moral. Nesse âmbito, é interessante destacar que a língua também é um meio de expressão dessas violências, pois os usos sociais de palavras e expressões podem carregá-las com efeitos de sentido ofensivos.

Vale ressaltar que as palavras e expressões não são, em si, depreciativas ou ofensivas, mas seu sentido, como afirmam Weinmann e Culau (2014, p. 633), "lhe[s] é dado pela trama discursiva em que ela[s] se encontra[m], trama essa que lança raízes em determinado caldo de cultura". Dessa forma, as práticas discursivas e as situações sociais de discriminação e preconceito é que conferem a expressões como "maricas" e “bicha” o seu caráter pejorativo.

Em relação ao contexto específico deste trabalho, destacamos, quanto às questões de violência através da língua, a importância do dicionário enquanto "saber vocabular de um grupo sócio-linguístico-cultural" (PIRES DE OLIVEIRA; ISQUERDO, 2001). O dicionário é tido como uma autoridade nos fatos da língua, no entanto, por se 
tratar de um texto, apresenta marcas históricas, culturais e ideológicas de seus autores e de seu tempo. Além da diferenciação das acepções de uma palavra, outro elemento do verbete que apresenta algumas nuances de sentido são as marcas de uso.

Os possíveis sentidos ofensivos e pejorativos de algumas palavras são apresentados aos consulentes através das marcas de uso. Apesar da importância das marcas ser reconhecida pelos estudiosos de Lexicografia, pouca atenção tem sido dada a esse elemento, tanto pelos dicionaristas como pelos estudiosos. No cenário internacional, os trabalhos de Fajardo (1997) e Garriga Escribano (1994; 1995) são representativos das discussões sobre marcas de uso na Lexicografia espanhola. No Brasil, temos os trabalhos de Strehler (2001; 2013), Araújo (2015) e Pontes (2012), dentre outros, tendo os dois últimos sido desenvolvidos no âmbito do Grupo de Pesquisa em Lexicografia, Terminologia e Ensino (LETENS) da Universidade Estadual do Ceará (UECE).

Dessa forma, nosso objetivo foi investigar, do ponto de vista da Metalexicografia, quais as marcas de uso utilizadas nos cinco dicionários escolares voltados para os anos finais do ensino fundamental do "Programa Nacional do Livro Didático - Dicionários" do ano de $2012^{1}$ para indicar os contextos de uso de palavras relacionadas à orientação sexual "homossexual", delimitada a pessoas do gênero masculino, bem como suas implicações para a compreensão dos sentidos ali expressos. Após levantarmos os verbetes relacionados a homossexual masculino em toda a nomenclatura de três obras, compusemos o corpus da pesquisa a partir das 11 entradas selecionadas nesses dicionários iniciais, buscando em seguida as mesmas entradas nas outras duas obras. Em seguida, estabelecemos as relações medioestruturais entre os verbetes de cada dicionário e analisamos as marcas de uso empregadas².

\footnotetext{
${ }^{1}$ No âmbito do "Programa Nacional do Livro Didático - Dicionários" de 2012, esses dicionários são chamados de dicionários tipo 3.

${ }^{2}$ Detalhes sobre a composição do corpus são melhor explicados na metodologia deste artigo.
} 
Em relação ao contexto acadêmico em que se insere nossa pesquisa, é importante destacar que se trata de um trabalho de Metalexicografia, compreendida aqui como a reflexão teórica sobre os dicionários (PORTO DAPENA, 2002). Vale ressaltar ainda que, por investigarmos a marcação em dicionários escolares, discutimos elementos ligados aos usos da língua e aos usos de dicionários em situações didáticas. Dessa forma, também se trata de uma pesquisa inserida no campo da Lexicografia Pedagógica, entendida como o campo de estudos que busca discutir as questões que envolvem os dicionários usados para o ensino-aprendizagem de língua materna ou estrangeira (PONTES, 2009).

Nossa pesquisa se justifica academicamente a partir das características apontadas até o momento: o estudo de elementos que carecem de discussão nos campos da Metalexicografia e da Lexicografia Pedagógica e a abrangência de nossa pesquisa, ou seja, os cinco dicionários tipo 3. Outra característica que merece destaque é a metodologia adotada, que favorece a compreensão do fenômeno da marcação e das relações entre os itens lexicais selecionados na pesquisa. Além disso, é importante ressaltar a necessidade de abrir espaços de discussão sobre as formas de expressão de preconceito e de violência através da língua, incluindo o seu regitro em obras lexicográficas.

Este artigo está dividido em cinco seções. A segunda seção trata da fundamentação teórica, em que discutimos aspectos relacionados ao dicionário e às marcas de uso. A terceira seção apresenta os aspectos metodológicos envolvidos na realização da pesquisa. A quarta seção apresenta os dados levantados e as discussões sobre as implicações do emprego das marcas encontradas. Por fim, a quinta seção apresenta nossas considerações finais. 


\section{Pressupostos teóricos}

O dicionário é um artefato cultural que apresenta um retrato do universo semântico-cultural de uma determinada comunidade linguística. Assim, ao analisar o sistema de marcas de uso de cinco dicionários escolares, exploramos como esses dicionários propõem restrições de uso às entradas que compõem nosso corpus.

Para compreendermos as marcas de uso de um dicionário, é importante situálas dentre as estruturas que compõem esse tipo de obra. Segundo Welker (2004), as estruturas lexicográficas são cinco, a saber: (1) a megaestrutura, estrutura global do dicionário em que se encaixam as demais; (2) a macroestrutura, corpo do dicionário, formado pelo conjunto de verbetes da obra; (3) a microestrutura, informações, presentes nos verbetes, de ordem ortográfico-gramatical, semântica e pragmática sobre as entradas que compõem a macroestrutura; (4) a medioestrutura, sistema de remissões entre as diferentes informações presentes no verbete ou em outras estruturas do dicionário; e (5) os textos externos, introduções, listas de abreviaturas, quadros de conjugação verbal que estão fora da macroestrutura e auxiliam na compreensão de informações presentes na obra. As marcas de uso são apresentadas ao consulente no guia de uso e na lista de abreviaturas, componentes dos textos externos, e estão no interior do verbete relacionadas ou à palavra entrada, ou à determinadas acepções.

De acordo com Welker (2004) e Pontes (2009), as informações mais usuais presentes no verbete lexicográfico são as seguintes: (1) informação fônica, informação sobre a pronúncia da entrada e suas variantes fonéticas; (2) informação gramatical, informação morfossintática a respeito da entrada; (3) marca de uso, informação sobre o contexto de utilização da entrada, podendo ser de ordem geográfica, social ou da área de conhecimento a que a entrada ou a acepção pertence; (4) definição, paráfrase semântica da palavra-entrada; (5) exemplo de uso, enunciado que mostra a palavra em uso; (6) colocação e fraseologia, construções sintáticas que apresentam a entrada como componente e apresentam certo grau de convencionalidade, caracterizando-se, 
por vezes, como subentradas, para as quais se apresentam definições próprias; e (7) remissiva, marcas que estabelecem conexões entre as informações no interior do verbete ou entre o verbete e as outras estruturas lexicográficas.

No âmbito da Metalexicografia, as marcas de uso são entendidas como etiquetas ou rótulos apresentados, na maioria das vezes, de maneira abreviada e acompanham as definições das palavras. As marcas podem contextualizar ou restringir os usos das palavras, sendo relacionadas à entrada em si ou a uma acepção particular, como ressalta Porto Dapena (2002, p. 251) ao afirmar que elas são "elementos indicadores de alguma característica relativa à natureza, ao uso ou ao valor da palavra-entrada em sua totalidade ou em algum de seus significados ou usos em particular".

Nesse contexto, é importante discutir os conceitos de marcação e de palavras marcadas e não marcadas. Fajardo (1997) propõe que a marcação seja compreendida como um procedimento lexicográfico para indicar particularidades do uso das palavras. Dessa forma, a marcação faz parte do planejamento necessário para delimitar a abrangência do universo lexical do dicionário e compõe um sistema de marcas de uso utilizadas ao longo da obra. Por isso, cada dicionário acaba adotando um sistema particular, o que pode gerar, consequentemente, um problema para os consulentes se não forem devidamente orientados.

O problema evidenciado por pesquisas sobre marcas de uso - como destacado por Welker (2004), Pontes (2009) e Strehler (2001) - é a ausência tanto de um padrão definido seguido pelos lexicógrafos quanto de indicações, no guia de uso da maioria dos dicionários, sobre o que é considerado "popular", "pejorativo" ou "chulo". Assim, o estabelecimento de critérios para a marcação pode ser confuso e subjetivo, dificultando a apreensão dos contextos de uso de algumas palavras ou suas acepções.

Através desses sistemas de marcação, as palavras e suas acepções podem ser classificadas em marcadas e não marcadas. Para compreendermos bem esses conceitos, recorremos à definição da funcionalidade das marcas de uso de Strehler 
(2001). O autor afirma que esse recurso lexicográfico serve para "caracterizar as palavras que fogem, sob certos aspectos, ao uso corriqueiro, normal, da língua de uma comunidade lingüística" (sic) (STREHLER, 2001, p. 174). Assim, as palavras que "fogem ao corriqueiro" aparecem marcadas no dicionário, isto é, apresentam uma indicação para o consulente de que aquele uso é um uso não convencional. Já as palavras que não "fogem" ao uso convencional não apresentam essas indicações, ou seja, são palavras não marcadas.

No entanto, se pensarmos que, em um mesmo dicionário, a palavra "pipa" pode aparecer sem marca de uso, enquanto a palavra "raia" pode aparecer marcada, fica perceptível o que leva a essa diferenciação. A nosso ver, o uso "normal" a que se refere Strehler (2001) seria o da norma de maior prestígio social. Portanto, o uso "corriqueiro" ou cotidiano pode ser, em muitos casos, um uso marcado se não fizer parte da norma prestigiada. Assim, existem questões socioculturais envolvidas nesse processo de marcação empreendido nas obras lexicográficas.

Existem várias possibilidades para a classificação das marcas de uso. Hausmann (1989) citado por Welker (2004, p. 131), por exemplo, apresenta uma lista mais detalhada de classificação das marcas de uso, a saber:

a) diacrônicas (por exemplo, antiquado, envelhecido, neologismo);

b) diatópicas (aplicadas a acepções restritas a certas regiões ou países);

c) diaintegrativas (usadas para assinalar estrangeirismos);

d) diamediais (diferenciam entre as linguagens oral e escrita);

e) diastráticas (por exemplo, chulo, familiar, coloquial, elevado);

f) diafásicas (diferenciam entre a linguagem formal e a informal);

g) diatextuais (assinalam que o lexema - ou acepção - é restrito a determinado gênero textual; por exemplo, poético, literário, jornalístico);

h) diatécnicas (informam que a acepção pertence a uma linguagem técnica, a um tecnoleto);

i) diafreqüentes (sic) (em geral: raro, muito raro);

j) diaevaluativas (mostram que o falante, ao usar o lexema, revela certa atitude; por exemplo, pejorativo, eufemismo);

k) dianormativas (indicam que o uso de certa acepção - ou lexema - é errado pelas normas da língua padrão). 
Fajardo (1997) faz considerações sobre sete tipos de marcas, a saber: as marcas diacrônicas; as marcas diatópicas; as marcas de nível, registro e estilo; as marcas técnicas; as marcas conotativas; as marcas de frequência; e as marcas normativas. Nesse contexto, um dos problemas destacados pelo autor é a classificação de algumas marcas, como a marca "familiar". Alguns estudiosos, como Hausmann (1989) citado por Welker (2004), incluem essa marca entre as marcas diastráticas, enquanto outros a tratam como diafásica. Fajardo (1997) ainda ressalta que, para alguns sociolinguistas, o registro de língua "familiar" não existiria; então, a inclusão dessa marca não faria sentido.

O autor destaca que essas classificações, bem como o sistema de marcação do dicionário, podem ser compreendidas como um sistema de oposições, indicando as seguintes:

1) atual // novo / obsolescente / obsoleto: neol., desus., antiq.

2) geral // regional / dialetal: Amér., And., Argent., Al.

3) neutro // falado / escrito: lit.

4) neutro // estrato / grupo: pop., vulg.

5) neutro // formal / informal: coloq., form., inform.

6) neutro // poético / literário/ jornalístico / administrativo: Adm., lit., Poét.

7) língua comum // língua técnica: Acúst., Aer., Agri., Agrim.

8) frequente // infrequente: desus., us.

9) neutro // conotado: deprec., irôn., insul.

10) correto // incorreto: /incor. (FARJADO, 1997, p. 36-37)

Essas oposições são construídas a partir de três diferentes processos, de acordo ainda com Fajardo (1997), a saber: (1) gradações, como "neutro - familiar - popular"; (2) antonímia, como "formal - informal"; e (3) delimitação, como "língua comum língua técnica". No entanto, como ressaltamos anteriormente, os limites entre alguns desses aspectos são muito vagos e até fluidos, dificultando a marcação das palavras no dicionário. 


\section{Metodologia}

Como nosso objetivo foi investigar a marcação de verbetes relacionados a homossexual masculino em dicionários escolares tipo 3, nosso trabalho pode ser caracterizado como uma pesquisa descritiva de caráter qualitativo. Os dicionários que serviram de fonte para a extração do corpus foram os seguintes:

1. DABL - Dicionário escolar da Academia Brasileira de Letras (BECHARA, 2011);

2. AJ - Aurélio Júnior - dicionário escolar da língua portuguesa (FERREIRA, 2011)

3. CA - Caldas Aulete - minidicionário contemporâneo da língua portuguesa (GEIGER, 2011);

4. DDLP - Dicionário didático da língua portuguesa (RAMOS, 2011); e

5. SJ - Saraiva jovem - dicionário da língua portuguesa ilustrado (SARAIVA; OLIVEIRA, 2010).

Inicialmente, realizamos a leitura integral de três dicionários (CA, DDLP e SJ), buscando as entradas referentes a homossexual masculino. Os critérios de escolha dos verbetes foram: (1) ser substantivo; (2) apresentar ao menos uma acepção referente a homossexual masculino. Essa busca resultou em uma lista de 11 entradas que foram consultadas nos outros dois dicionários (DABL e AJ) para a composição do corpus principal de nossa pesquisa. O Quadro 1 mostra: as entradas; quais e quantos verbetes aparecem em cada dicionário; os verbetes sem acepção referente a homossexual masculino também por dicionário, indicados com um asterisco $\left(^{*}\right)$ e desconsiderados na análise; o número total de ocorrências dos verbetes, considerando-se os cinco dicionários. 
Quadro 1 - Corpus principal.

\begin{tabular}{|l|l|l|l|l|l|l|}
\hline Entradas & DABL (7) & AJ (8* / 4) & CA (10) & DDLP (10) & SJ (9) & Total \\
\hline Baitola & ---- & ---- & Baitola & Baitola & Baitola & \\
\hline Bicha & Bicha & Bicha* & Bicha & Bicha & Bicha \\
\hline Boiola & ---- & ---- & Boiola & Boiola & Boiola \\
\hline Boneca & Boneca & Boneca* & Boneca & Boneca & Boneca \\
\hline Gay & Gay & Gay & Gay & Gay & Gay & \multirow{2}{*}{40} \\
\hline Homo & ---- & Homo* & ---- & Homo & ---- & \\
\hline Homossexual & Homossexual & Homossexual & Homossexual & Homossexual & Homossexual \\
\hline Maricas & Maricas & Maricas & Maricas & Maricas & Maricas \\
\hline Mariquinhas & ---- & ---- & Mariquinhas & ---- & ---- \\
\hline Pederasta & Pederasta & Pederasta & Pederasta & Pederasta & Pederasta & \\
\hline Veado & Veado & Veado* & Veado & Veado & Veado & \\
\hline
\end{tabular}

A partir das definições dos verbetes do corpus principal, sentimos a necessidade de elaborar um corpus complementar para observar as relações de remissão entre as entradas do corpus em cada dicionário por meio de uma rede medioestrutural. Os verbetes que compõem o corpus complementar são: "afeminado", "efeminado", "heterossexual", "homossexualidade", "homossexualismo" e "pederastia". É importante ressaltar que esses verbetes não apresentam definições diretamente relacionadas a homossexual masculino, nosso critério de composição do corpus principal, mas a relação com o homossexual é feita através de remissivas. Recorremos a esses verbetes em nossas análises quando as definições das entradas do corpus principal apontam para as entradas do corpus complementar.

Inicialmente, após a leitura dos verbetes do corpus principal nos cinco dicionários, percebemos que as definições utilizadas formavam um fluxo de informações entre eles. Dessa forma, elaboramos uma rede de sentidos, que denominamos de rede medioestrutural, entre os verbetes do corpus principal, recorrendo ao corpus complementar para evidenciar as relações de sentido construídas através da medioestrutura dos dicionários. A partir dessas redes, apresentadas na próxima seção, discutimos as implicações da marcação utilizada em cada dicionário nos verbetes em análise. 


\section{Análises e resultados}

Primeiramente, discutimos os dados relacionados a cada dicionário individualmente, seguindo a ordem estabelecida na seção anterior. Em seguida, discutimos as implicações gerais de nossos achados. Apresentamos, no Quadro 2, as acepções selecionadas do DABL.

Quadro 2 - Acepções do DABL.

\begin{tabular}{|c|c|}
\hline Entradas & Acepções selecionadas \\
\hline Bicha & 3. pej. Homossexual masculino. \\
\hline Boneca & 5. pej. Homem efeminado. \\
\hline \multirow{3}{*}{ Gay } & 1. Homossexual, geralmente referido ao sexo masculino. \\
\hline & 2. Homossexual. \\
\hline & 3. Referente ou próprio de homossexual. \\
\hline \multirow[t]{2}{*}{ Homossexual } & $\begin{array}{l}\text { 1. Que sente atração por ou tem relações sexuais com indivíduo do } \\
\text { mesmo sexo. }\end{array}$ \\
\hline & 2. Pessoa homossexual. \\
\hline \multirow{2}{*}{ Maricas } & 1. pej. Homem efeminado. \\
\hline & 3. Que é efeminado ou medroso. \\
\hline Pederasta & Homem que tem relações sexuais com outro homem; homossexual. \\
\hline Veado & 2. chulo Homem homossexual. \\
\hline
\end{tabular}

Fonte: adaptado de Santos (2016, p. 66).

Como é possível perceber, seis acepções das onze encontradas não apresentam marcas de uso, são elas: as três acepções do verbete "gay", as duas do verbete "homossexual" e a do verbete "pederasta". Em relação às marcas de uso empregadas, das onze acepções em análise três apresentam a marca "pej.", de pejorativo, e uma apresenta a marca "chulo". Os verbetes que apresentam essas marcas são, respectivamente, "bicha", "boneca", "maricas" e "veado". Como afirmamos anteriormente, as marcas são utilizadas para indicar ao consulente os contextos em que as palavras são utilizadas ou as nuances de sentido que seus usos podem apresentar. Nos casos em análise, temos exemplos de como as marcas indicam essas nuances de sentido ao marcar acepções de verbetes referentes a palavras que apresentam uma avaliação social negativa em relação ao homossexual masculino. No 
entanto, é interessante observar como essas marcas de uso estão posicionadas na rede medioestrutural proposta pelo DABL para os verbetes em análise.

A partir das definições apresentadas acima, elaboramos a rede medioestrutural que subjaz a esses verbetes. É possível perceber, no Quadro 2, que o verbete "bicha" conduz o consulente ao verbete "homossexual". Já o verbete "boneca" levaria o consulente ao verbete "efeminado" do corpus complementar, que apresenta as seguintes definições: “2. Homossexual. 3. Aquele que é homossexual”3. Assim, o verbete "efeminado" conduz ao verbete "homossexual". O verbete "gay", em suas três acepções, conduz o leitor à consulta do verbete "homossexual". O verbete "maricas", como ocorre com o verbete "boneca", conduz o consulente ao verbete "efeminado" e, como apontado no verbete "boneca", para o verbete "homossexual". O verbete "pederasta" apresenta uma definição mais informativa e, em seguida, faz uma remissão implícita ao verbete "homossexual". O verbete "veado" conduz ao verbete "homossexual". Dessa forma, seis verbetes conduzem o consulente, direta ou indiretamente, a "homossexual", o sétimo verbete, que apresenta uma definição mais informativa e que, de fato, responderia à dúvida de significado que originou a consulta. Assim, temos a Figura 1:

Figura 1 - Rede medioestrutural do DABL com marcas de uso.

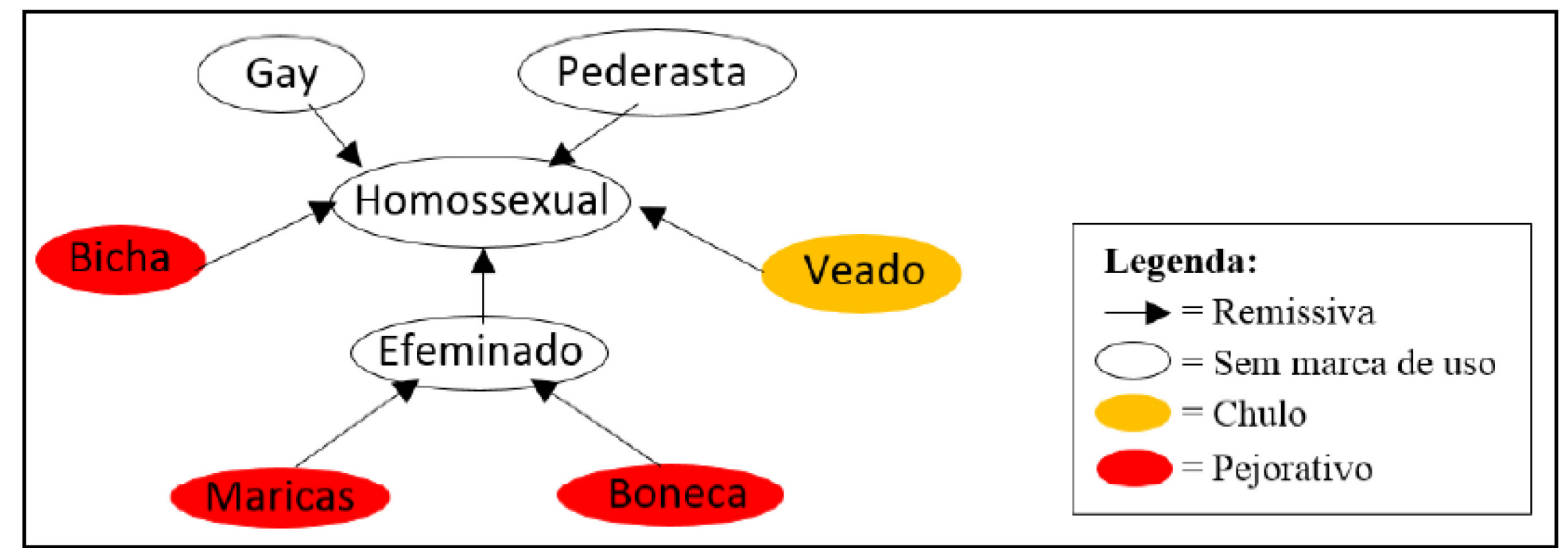

Fonte: Santos (2016, p. 65).

${ }^{3}$ É importante ressaltar que, por rigor metodológico, essa entrada não compôs o corpus principal por não se enquadrar nos critérios de seleção apontados na metodologia. 
As marcas de uso utilizadas nesse conjunto de verbetes ficam posicionadas nas bordas da rede medioestrutural. Essa organização sugere que, ao seguir o fluxo de sentidos, o consulente vai ser direcionado de palavras marcadas negativamente para palavras de uso social não-marcado. Assim, o dicionário orienta, de forma implícita, que o consulente deve preferir utilizar as palavras não-marcadas em detrimento das palavras marcadas. Essa percepção decorre do fluxo de sentido de busca expresso pelas relações remissivas entre as entradas. Para tanto, a ausência de definições que apresentem o significado da entrada colabora para que o consulente precise fazer nova consulta. A nosso ver, esse fluxo de sentidos se configura como um aspecto positivo desse dicionário por contribuir para a construção de práticas de linguagem menos preconceituosas. Partiremos, agora, para os dados extraídos do AJ, apresentados no Quadro 3.

Quadro 3 - Acepções do AJ.

\begin{tabular}{|l|l|}
\hline \multicolumn{1}{|c|}{ Entradas } & \multicolumn{1}{c|}{ Acepções selecionadas } \\
\hline \multirow{2}{*}{ Gay } & 1. Que é homossexual. \\
\cline { 2 - 3 } & 2. Homossexual. \\
\hline \multirow{2}{*}{ Homossexual } & 1. Pessoa que sente atração sexual por pessoas do mesmo sexo. \\
\cline { 2 - 2 } Maricas & 2. De, ou relativo a homossexual (1). \\
\hline Pederasta & Indivíduo efeminado, ou medroso. \\
\hline \multicolumn{2}{|c|}{ Fonele que é dado à pederastia. } \\
\hline
\end{tabular}

Em relação às marcas de uso, nenhuma das acepções encontradas apresenta marcação. É importante destacar, no entanto, que o dicionário não registra acepções em três verbetes que foram marcados no dicionário anterior, a saber, "bicha", "boneca" e "veado". Ainda em comparação com o dicionário anterior, também não há marcação no verbete "maricas", apontado como pejorativo no DABL. É importante destacar que no AJ não estão presentes os verbetes "baitola" e "boiola". Em todos esses casos, como vimos no DABL e veremos nos outros dicionários analisados, haveria grande probalidade de marcação. 
Assim como no conjunto anterior de verbetes, a partir das definições e de suas remissivas, elaboramos a rede medioestrutural do AJ, apresentada na Figura 2:

Figura 2 - Rede medioestrutural do AJ.

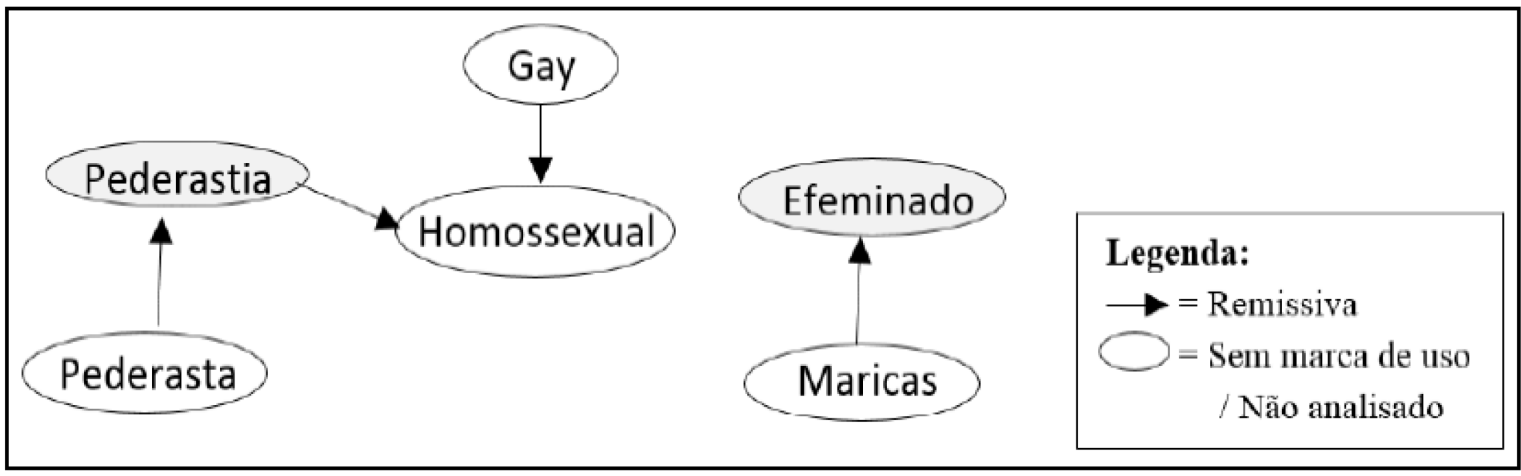

Fonte: Santos (2016, p. 73)

Nessa figura, é possível perceber a existência de dois grupos separados de relações: o primeiro centrado na entrada "homossexual" e o segundo, na entrada "efeminado". No primeiro grupo, é possível observar a mesma orientação implícita para a utilização da palavra "homossexual" em detrimento das demais. No entanto, a ausência de marcas de uso dificulta a compreensão dos motivos dessa orientação. Supomos que essa relação decorra da aparente pertença dessa palavra ao discurso das ciências biológicas e da saúde. Portanto, "homossexual" seria utilizada em contextos mais formais que as demais.

Embora não seja possível identificar a motivação dessa organização de remissões, esse aspecto se configura como positivo. Como afirmamos na análise da Figura 1, a orientação encontrada pode auxiliar na construção de usos linguísticos menos preconceituosos.

Por fim, é importante destacar a ausência de relação entre os verbetes "efeminado" e "homossexual". Na rede medioestrutural anterior, havia uma relação entre esses verbetes, mas, aqui, essa relação não ocorre. A falta dessa relação pode indicar que não há uma associação necessária entre a homossexualidade e a identificação com práticas tidas como femininas. Essa dissociação é outro aspecto 
positivo, em nosso entendimento, pois pode contribuir para a desconstrução de preconceitos em relação ao homossexual masculino. Partiremos para o conjunto de acepções extraídas do CA, presentes no Quadro 4.

Quadro 4-Acepções do CA.

\begin{tabular}{|c|c|}
\hline Entradas & Acepções selecionadas \\
\hline Baitola & N.E. Gír. Pej. Ver boiola. (ø) \\
\hline Bicha & 4 Bras. Vulg. Pej. Homossexual masculino, homem efeminado. \\
\hline Boiola & Pej. Pop. Homossexual do sexo masculino; BAITOLA. \\
\hline Boneca & 6 Bras. Pej. Homem efeminado. \\
\hline \multirow{3}{*}{ Gay } & 1 Homem homossexual. \\
\hline & 2 Homossexual. \\
\hline & 3 Próprio ou típico de homossexual \\
\hline Homossexual & $\begin{array}{l}\text { Que ou quem sente atração por e/ou tem relações sexuais com pessoas do } \\
\text { mesmo sexo. }\end{array}$ \\
\hline Maricas & Pej. Pop. Que ou quem é afeminado ou medroso (diz-se de homem ou garoto). \\
\hline Mariquinhas & Pej. Pop. Ver maricas. (ø) \\
\hline Pederasta & $\begin{array}{l}\text { Homem que tem relações sexuais com pessoas do mesmo sexo; } \\
\text { HOMOSSEXUAL. }\end{array}$ \\
\hline Veado & 2 Bras. Tabu. Homem homossexual. \\
\hline
\end{tabular}

Fonte: adaptado de Santos (2016, p. 83).

Em relação às marcas de uso empregadas, temos que, das doze acepções em análise, cinco não apresentam marca alguma, a saber, as três acepções do verbete "gay", a definição dos verbetes "homossexual" e "pederasta". A marca "Pej.", de pejorativo, aparece em seis verbetes: "baitola", “bicha”, "boiola”, “boneca”, "maricas” e "mariquinhas". A marca "Pop.", de popular, aparece em três verbetes: "boiola", "maricas" e "mariquinhas". O mesmo ocorre com a marca "Bras.", referente a brasileirismo, que aparece em "bicha”, “boneca” e “veado”. As marcas “NE”, "Gír.", "Vulg." e "Tabu." - referentes, respectivamente, a linguagem do nordeste, vocábulo gírio, vocábulo vulgar e tabuísmo - aparecem apenas uma vez. As marcas "NE" e "Gír." aparecem no verbete "baitola"; a marca "Vulg.", no verbete "bicha"; e a marca "Tabu.", no verbete "veado".

Nesse conjunto de verbetes, é possível perceber que o dicionarista buscou usar uma maior variedade de marcas para indicar as nuances de sentido presentes nos usos 
das diferentes entradas que se referem a homossexual masculino. Essa variedade pode contribuir para uma melhor percepção sobre os contextos de uso desses itens lexicais por parte do consulente. Em relação à rede medioestrutural, vejamos a Figura 3.

Figura 3 - Rede medioestrutural do CA com marcações.

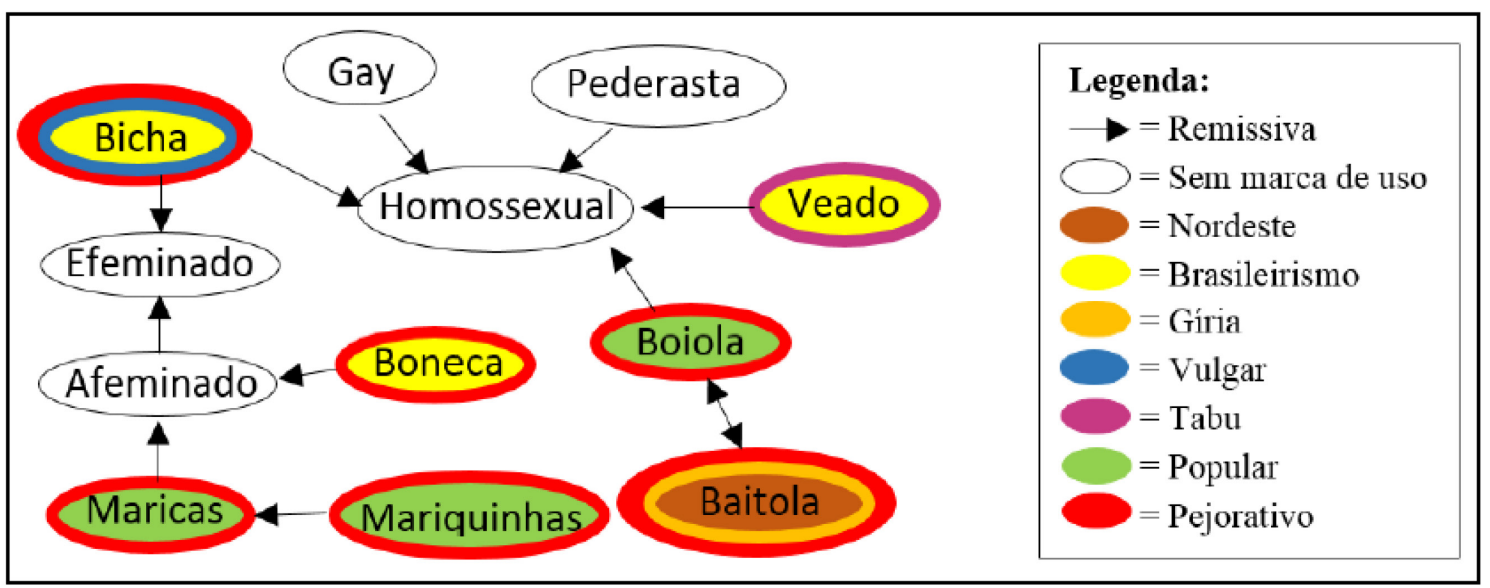

Fonte: Santos (2016, p. 82).

É interessante observar que, como ocorreu com os verbetes do DABL, as marcas de uso estão posicionadas nas margens da rede. A rede de sentidos é bem complexa e tem, como centro, o verbete "homossexual". Dessa forma, o consulente é levado, ao seguir o fluxo de sentidos, de palavras negativamente marcadas para palavras de uso social não marcado. Um aspecto interessante a ser destacado é que a complexidade da rede pode indicar, em relação à consulta, uma dificuldade de encontrar as informações desejadas. Os verbetes "maricas" e "boneca", por exemplo, apresentam o maior caminho de busca a ser percorrido pelo consulente. Assim, o consulente, se não for bem orientado pelo dicionário ou pelo professor, pode desistir da busca e ficar sem a informação desejada.

Partiremos, agora, para o conjunto de verbetes do DDLP, apresentados no Quadro 5. 
Quadro 5 - Acepções do DDLP.

\begin{tabular}{|c|c|}
\hline Entradas & Acepções selecionadas \\
\hline Baitola & pejorativo Homossexual masculino. \\
\hline Bicha & pejorativo Homem afeminado. \\
\hline Boiola & pejorativo Homossexual masculino. \\
\hline \multirow[b]{2}{*}{ Boneca } & 3 pejorativo Pessoa do sexo masculino que é afeminada. \\
\hline & $\begin{array}{l}4 \text { popular Homossexual masculino que se veste com roupas próprias do sexo } \\
\text { feminino. }\end{array}$ \\
\hline \multirow{2}{*}{ Gay } & 1 Da homossexualidade ou relacionado a ela. \\
\hline & 2 Pessoa homossexual. \\
\hline Homo & $>$ Homossexual. (ø) \\
\hline \multirow{2}{*}{ Homossexual } & 1 Da homossexualidade ou relacionado a ela. \\
\hline & 2 Que ou quem sente atração sexual por indivíduos do mesmo sexo. \\
\hline Maricas & 1 popular Em relação a uma pessoa do sexo masculino, que é afeminada. \\
\hline \multirow{2}{*}{ Pederasta } & 1 pejorativo Homem homossexual. \\
\hline & 2 pejorativo Homem adulto que tem relações sexuais com um rapaz. \\
\hline Veado & 2 pejorativo Homossexual masculino. \\
\hline
\end{tabular}

Fonte: adaptado de Santos (2016, p. 93).

No conjunto de verbetes extraído do DDLP, novamente os verbetes "gay" e "homossexual" aparecem sem marcas de uso. O verbete "homo" também não é marcado e não apresenta definição, apenas a remissiva ao verbete "homossexual". Sobre as marcas de uso, apenas duas são utilizadas, a saber, "pejorativo" e "popular". A primeira é usada em oito acepções e a segunda, em duas. Por fim, é interessante destacar que, diferente do que ocorreu nos dicionários anteriores, o verbete "pederasta" aparece marcado como "pejorativo". Sobre a rede medioestrutural, vejamos a Figura 4.

Figura 4 - Rede medioestrutural do DDLP com marcações.

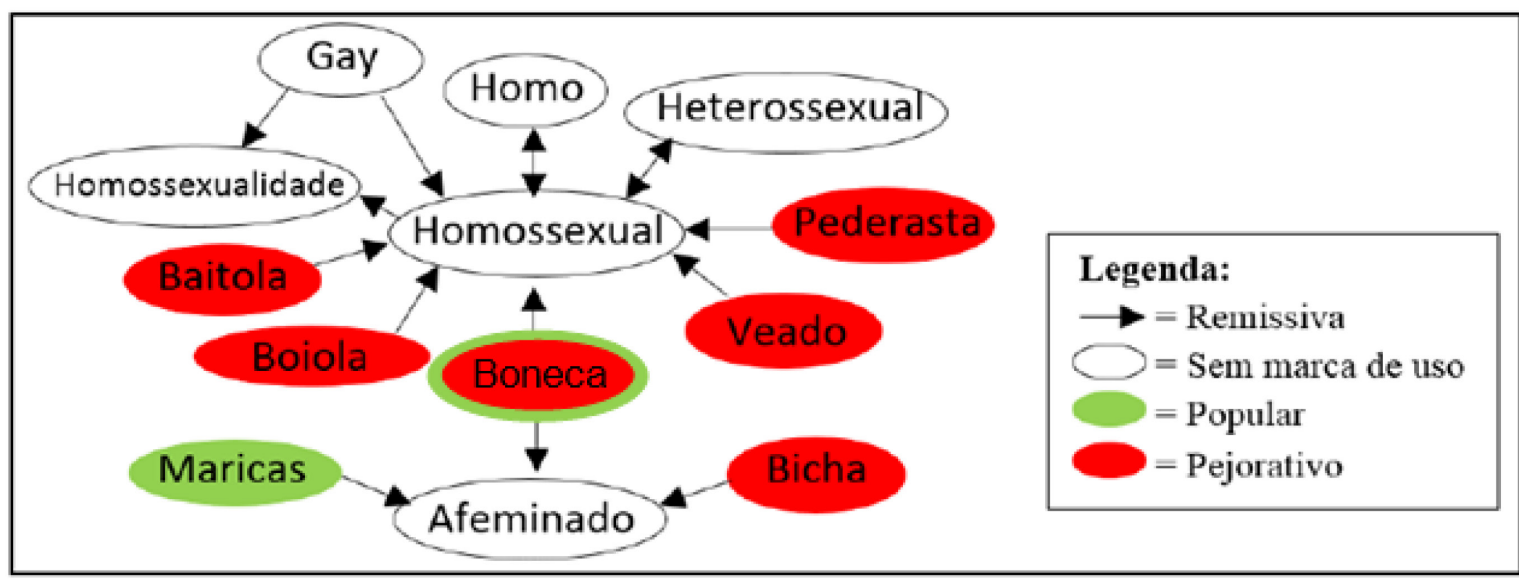

Fonte: Santos (2016, p. 92). 
A partir da Figura 4, é possível perceber que não encontramos uma variedade de marcas de uso e, para as entradas selecionadas, o dicionário apresenta um sistema simples de marcação. De maneira recorrente, os verbetes marcados aparecem posicionados ao redor do verbete "homossexual". Pela quarta vez, observamos, a partir das remissões entre os verbetes, a orientação implícita de uso da palavra "homossexual" em detrimento das palavras marcadas. A nosso ver, é um aspecto positivo desse dicionário por contribuir para a construção de práticas de linguagem menos preconceituosas.

É interessante destacar que, como ocorreu na análise referente à Figura 2, o verbete "afeminado" não apresenta relação direta com o verbete "homossexual". Essa ausência de remissão pode indicar, como no caso anterior, a dissociação entre a homossexualidade e a identificação com as expressões tidas como femininas. No entanto, os verbetes "bicha", "boneca" e "maricas" apresentam remissão para o verbete "afeminado". Dessa forma, o dicionário parece indicar que há diferentes comportamentos e posicionamentos em relação a expressão social da homossexualidade masculina.

Por fim, outro detalhe interessante é a presença de remissivas no verbete "homossexual". Nos dicionários anteriores, esse verbete é tratado como alvo das remissivas, mas, aqui, há remissivas que partem dessa entrada para os verbetes "homo", "heterossexual" e "homossexualidade", todos não marcados. Assim, o dicionário aponta entradas socialmente neutras para complementar as informações obtidas na entrada "homossexual", contribuindo para a ampliação dos conhecimentos lexicais do consulente sobre os usos socialmente não marcados da entrada. Partiremos, agora, para o último conjunto de verbetes, os que foram extraídos do SJ. 
Quadro 6 - Acepções do SJ.

\begin{tabular}{|c|c|}
\hline Entradas & Acepções selecionadas \\
\hline Baitola & $N E$ gír $M q$ Boiola. \\
\hline Bicha & 3. Bras vulg Homossexual masculino. \\
\hline Boiola & pej Homossexual do sexo masculino, gay. \\
\hline Boneca & 4. pej Homossexual masculino. \\
\hline \multirow{2}{*}{ Gay } & 1. Homossexual. \\
\hline & 2. Relativo aos homossexuais. \\
\hline \multirow{2}{*}{ Homossexual } & 1. Relacionado ao interesse sexual ou amoroso por pessoas do mesmo sexo. \\
\hline & 2. Pessoa que tem esse interesse. \\
\hline Maricas & $\begin{array}{l}\text { pej pop Que ou quem se amedronta com facilidade ou tem modos } \\
\text { afeminados. }\end{array}$ \\
\hline Pederasta & $\begin{array}{l}\text { Homem que mantém relações sexuais com outro homem; homossexual } \\
\text { masculino. }\end{array}$ \\
\hline Veado & 2. pej Homem homossexual. \\
\hline
\end{tabular}

Fonte: adaptado de Santos (2016, p. 104).

Dentre as onze acepções em análise, cinco não são marcadas, a saber, as duas do verbete "gay", as duas do verbete "homossexual" e a do verbete "pederasta". Novamente, a marca mais utilizada é a que se refere ao uso pejorativo, "pej", presente nos verbetes "boiola", "boneca", "maricas" e "veado". O verbete "maricas" apresenta também única ocorrência da marca que se refere à linguagem popular, "pop". $\mathrm{O}$ verbete "baitola" apresenta as únicas ocorrências das marcas referentes à linguagem do nordeste, "NE", e a vocábulo gírio, "gír". A abreviatura " $M q$ " pode ser compreendida como um indicativo de remissão, pois significa "mesmo que" e é seguida pela remissiva, não havendo definição neste verbete. Por fim, o verbete "bicha" também apresenta as únicas ocorrências das marcas referentes a brasileirismo, "Bras", e a linguagem vulgar, "vulg". Vejamos como fica a rede medioestrutural proposta pelo dicionário entre esses verbetes, na Figura 5. 
Figura 5 - Rede medioestrutural do SJ com marcações.

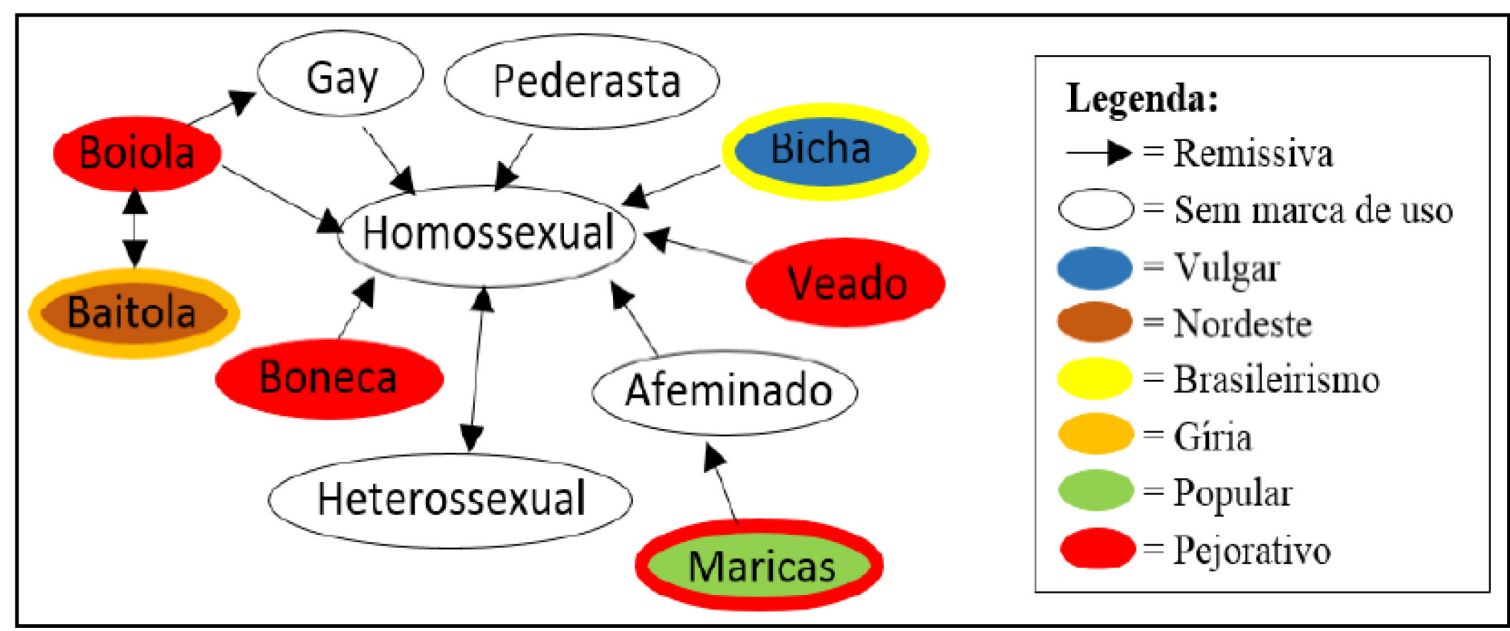

Fonte: Santos (2016, p. 103).

Novamente, é possível perceber que o centro da rede é o verbete "homossexual" e que as entradas marcadas estão às margens da rede. Como temos afirmado, essa organização é um aspecto positivo por conduzir o consulente aos usos não marcados da língua e contribuir para a desconstrução de práticas de linguagem preconceituosas. De forma semelhante ao que ocorreu no dicionário anterior, a entrada "homossexual" apresenta uma remissão ao verbete "heterossexual", buscando complementar as informações obtidas em "homossexual" e ampliando os conhecimentos do consulente.

Como já comentamos o padrão de marcação de cada obra, vejamos, no Quadro 7, o padrão de marcação para cada entrada.

Quadro 7 - Visão geral sobre as marcas de uso.

\begin{tabular}{|l|l|l|l|l|l|}
\hline \multicolumn{1}{|c|}{ Entradas } & DABL & AJ & \multicolumn{1}{c|}{ CA } & DDLP & \multicolumn{1}{c|}{ SJ } \\
\hline Baitola & ---- & ---- & N.E. Gír. Pej. & Pej. & N.E. Gír. \\
\hline Bicha & Pej. & ---- & Bras. Vulg. Pej. & Pej. & Bras. Vulg. \\
\hline Boiola & ---- & ---- & Pej. Pop. & Pej. & Pej. \\
\hline Boneca & Pej. & ---- & Bras. Pej. & Pop. & Pej. \\
\hline Gay & $\varnothing$ & $\varnothing$ & $\varnothing$ & $\varnothing$ & $\varnothing$ \\
\hline Homo & ---- & ---- & ---- & $\varnothing$ & ---- \\
\hline Homossexual & $\varnothing$ & $\varnothing$ & $\varnothing$ & $\varnothing$ & $\varnothing$ \\
\hline Maricas & Pej. & $\varnothing$ & Pej. Pop. & Pop. & Pej. Pop. \\
\hline Mariquinhas & ---- & ---- & Pej. Pop. & ---- & ---- \\
\hline Pederasta & $\varnothing$ & $\varnothing$ & $\varnothing$ & Pej. & $\varnothing$ \\
\hline Veado & Chulo & ---- & Bras. Tabu & Pej. & Pej. \\
\hline
\end{tabular}

Fonte: Santos (2016, p. 107). 
Os verbetes "gay", "homossexual" e "homo" aparecem, em todo o nosso corpus, não marcados, apontando para um caráter neutro dessas palavras. $O$ verbete "pederasta", presente nos cinco dicionários, apresenta apenas uma ocorrência da marca "pej.". Então, de acordo com os dados levantados em nosso corpus, poderíamos dizer que é uma palavra neutra, no entanto, é necessário fazer uma ressalva. Há uma confusão entre as palavras "pederastia" e "pedofilia" no senso comum, como atestado nos dicionários Aurélio (FERREIRA, 2016), Michaelis (2018) e Priberam (2013). Assim, ocorre uma associação entre a pederastia, que envolve a relação entre um homem mais velho e um homem mais novo, e o abuso de menores de idade. Dessa forma, é possível perceber que a palavra "pederasta" tem seus sentidos marcados por aspectos negativos apesar da quase ausência de marcas negativas.

O verbete "baitola", com três ocorrências em nosso corpus, apresenta duas marcas diatópicas, indicativas de um falar típico da região nordeste (N.E.), duas marcas indicativas de vocábulo gírio (gír.) e outras duas marcas referentes a uso pejorativo. É interessante destacar que as marcas de gíria e de pejorativo representam aspectos de valoração negativa para a palavra, de menosprezo (GARRIGA ESCRIBANO, 1994-1995), embora nem toda gíria seja, de fato, pejorativa. É importante destacar que apenas SJ não apresenta a marca de pejorativo, o que, a nosso ver, pode se configurar como uma omissão da obra e contribuir para o uso inadequado dessa entrada.

No verbete "bicha", encontramos três ocorrências da marca referente a uso "pejorativo", duas ocorrências da marca "vulgar" e duas ocorrências da marca diatópica referente a "brasileirismo". As conotações negativas dessa entrada estão indicadas pelas duas primeiras marcas. A marca "vulgar", segundo Garriga Escribano (1994), apresenta três conotações, a saber, (1) a sexual, relacionada ao ato sexual ou aos órgãos sexuais; (2) a criminosa, relacionada a atos criminosos como roubos, armas e delitos; e a dos insultos, como palavrões e palavras de baixo calão. Dessa forma, de 
acordo com os dicionários em análise, a entrada "bicha" é usada em contextos depreciativos, portanto, estaria inserida em práticas de linguagem preconceituosas.

O verbete "boiola" apresenta três ocorrências da marca referente ao uso pejorativo e uma ocorrência da marca referente ao registro popular da língua. A marca "popular", assim como a marca "familiar" discutida anteriormente, apresenta uma delimitação imprecisa em relação aos diversos usos da língua. Novamente, de acordo com nosso corpus, observamos que o uso do vocábulo é marcado por uma conotação negativa, estando presente em contextos preconceituosos de uso da língua.

O verbete "boneca" também é marcado pelo uso depreciativo indicado nas três ocorrências da marca "pej.". Além dessas três ocorrências, temos uma ocorrência da marca diatópica referente ao falar típico do Brasil e uma ocorrência da marca referente à linguagem popular. Neste último caso, ao apresentar apenas a marca "Pop.", o DDLP pode contribuir para o uso inadequado da entrada, dando margem para que o consulente interprete que a entrada naquela acepção pode ser usada em contextos informais de interação.

O verbete "maricas" apresenta três ocorrências da marca "pejorativo" e três ocorrências da marca "popular". O verbete "mariquinhas" segue a mesma marcação de "maricas", apresentando uma ocorrência da marca "pejorativo" e uma ocorrência da marca "popular". Dessa forma, o caráter depreciativo desses vocábulos é sinalizado pela marca de uso "pejorativo". No entanto, nem AJ nem DDLP apresentam essa marcação. AJ opta por não apresentar nenhuma marca para essa entrada, enquanto DDLP marca a entrada como pertencente à linguagem popular. Em ambos os casos, a omissão do aspecto depreciativo do uso da entrada pode contribuir para o uso inadequado da entrada pelo consulente.

O verbete "veado" apresenta duas ocorrências da marca "pejorativo", uma ocorrência da marca "brasileirismo", uma ocorrência da marca "chulo" e uma ocorrência da marca "tabu". Novamente, as marcas apontam um uso de valoração 
negativa dessa palavra, bem como o aspecto proibitivo de seu uso por se tratar de um tabu linguístico. De acordo com nossos achados, essa entrada está associada a contextos depreciativos e preconceituosos.

Nesse ponto, acreditamos ser necessário destacar que as palavras "bicha", "baitola" e "veado", indicadas como preconceituosas e depreciativas até o momento, são utilizadas entre sujeitos homossexuais em suas interações, geralmente, sem a conotação negativa. A conotação depreciativa estaria mais presente em situações de interação entre indivíduos de orientação sexual heterossexual e em situações de interação formais. Assim, com o objetivo de orientar o consulente sobre os usos formais da língua, os dicionários em análise precisam apresentar as marcas de uso encontradas.

Por fim, é interessante destacar que, como ficou claro na observação das redes medioestruturais, o fluxo de sentidos leva o consulente das entradas marcadas para as entradas não marcadas. Dessa forma, os dicionários em análise, até por se tratarem de obras para uso escolar, conduzem o consulente às entradas pertencentes à norma padrão, as quais seriam as palavras usadas em um discurso politicamente correto. Logo, esse aspecto, a nosso ver, não é, em si, um aspecto negativo, tendo em vista que as marcas de uso ajudam a compreender as nuances de sentido entre as entradas, apontando aquelas que devem ser evitadas por serem desrespeitosas e pejorativas.

Apesar de em todos os casos os consulentes serem levados das entradas marcadas às não marcadas, que correspondem às aceitas por homossexuais, houve as omissões das obras como apontamos anteriormente. Essas omissões podem acarretar o uso inadequado das entradas pelos consulentes, bem como contribuir para a manutenção de usos preconceituosos de linguagem em relação aos homossexuais. Dessa forma, é necessário que as obras lexicográficas procurem esclarecer o consulente de forma apropriada para a compreensão dos recursos utilizados na obra, instrumentalizando seus usuários para o uso da língua em diferentes contextos. 


\section{Considerações finais}

Após a discussão dos dados, é necessário fazer algumas considerações sobre a pesquisa. O objetivo era investigar a marcação utilizada nos dicionários escolares tipo 3 do "PNLD - Dicionários 2012" para indicar as restrições e os contextos de uso de palavras relacionadas a homossexual masculino, bem como suas implicações para a compreensão dos sentidos ali expressos.

A maior ocorrência, em nosso corpus, foi a da marca que se refere ao uso pejorativo, indicando possíveis contextos discriminatórios em que as palavras analisadas são empregadas. As palavras marcadas - como "bicha", "baitola" e "maricas", por exemplo - estão posicionadas às margens das redes medioestruturais e o fluxo de sentidos converge dessas palavras para as palavras não marcadas, "gay" e "homossexual", por exemplo. A nosso ver, essa orientação, mesmo que implícita, é um aspecto positivo em relação às práticas de linguagem que envolvem a figura do sujeito homossexual masculino, tendo em vista que o uso de palavras não marcadas pode contribuir para a construção de práticas sociais menos preconceituosas.

Os dicionários escolares analisados mostraram diferentes formas de marcar as palavras em análise e de estabelecer o fluxo de sentidos entre os verbetes. O fluxo adotado pelos cinco dicionários, o de remeter as palavras marcadas negativamente às palavras neutras, pode favorecer que os consulentes/estudantes identifiquem as palavras que devem ser evitadas ao se referirem ao sujeito homossexual.

Portanto, em contexto de educação, discutir as diferentes formas de se referir ao sujeito homossexual em diferentes contextos e gêneros discursivos/textuais, usando os dicionários para estabelecer interação com outros textos e também com as experiências individuais dos alunos, pode ser uma atividade produtiva, tanto para as questões de produção escrita como para a reflexão sobre os usos da língua, ressaltando o cuidado em evitar os usos desrespeitosos/discriminatórios, como indicados aqui. 
Essa mesma metodologia pode ser utilizada com outros conjuntos de verbetes, como verbetes sobre religião, a mulher, as pessoas transexuais, os negros etc. Os alunos serão levados a discutir essas temáticas e, em conjunto, expor suas ideias e experiências, desenvolvendo seu senso crítico sobre a língua e seus usos.

\section{Referências Bibliográficas}

ARAÚJO, N. C. A gíria como marca de uso nos dicionários escolares. 2015. 68f. Monografia (graduação em Letras) - Curso de Letras, Centro de Humanidades, Universidade Estadual do Ceará. Fortaleza, 2015.

BECHARA, E. C. (org.). Dicionário escolar da Academia Brasileira de Letras. 3. ed. São Paulo: Cia. Ed. Nacional, 2011.

BRASIL. Ministério da Educação. Secretaria de Educação Básica. Com direito à palavra: dicionários em sala de aula. Brasília: MEC, SEB, 2012. Disponível em: http://portal.mec.gov.br/index.php?option=com docman\&task=doc download\&gid= 12059\&Itemid=. Acesso em: jan. 2018.

FAJARDO, A. Las marcas lexicográficas: concepto y aplicación práctica en la Lexicografía española. Revista de Lexicografía, v. III, p. 31-57, 1996-1997.

FERREIRA, A. B. de H. Pederastia. Dicionário Aurélio de português online. Disponível em: https://dicionariodoaurelio.com/pederastia. Acesso em: jan. 2018.

FERREIRA, A. B. de H. Aurélio Júnior: dicionário escolar da língua portuguesa. 2. ed. Curitiba: Positivo, 2011.

GARRIGA ESCRIBANO, C. Las marcas de uso: despectivo en el DRAE. Revista de Lexicografía, v. I., p. 113-147, 1994-1995.

GARRIGA ESCRIBANO, C. La marca de "vulgar" en el DRAE: de "Autoridades" a 1992. Sintagma, v. 6, p. 5-13, 1994.

GEIGER, P. (org.). Caldas Aulete: minidicionário contemporâneo da língua portuguesa. 3. ed. Rio de Janeiro: Lexikon, 2011.

MICHAELIS. Pederastia. Michaelis: dicionário brasileiro de língua portuguesa. São Paulo: Melhoramentos, 2018. Disponível em: 
http://michaelis.uol.com.br/moderno-portugues/busca/portuguesbrasileiro/pederastia/. Acesso em: jan. 2018.

PIRES DE OLIVEIRA, A. M. P.; ISQUERDO, A. N. Apresentação. In: PIRES DE OLIVEIRA, A. M. P.; ISQUERDO, A. N. (Orgs.). As ciências do léxico: lexicologia, lexicografia, terminologia. 2. ed. Campo Grande, MS: EdUFMS, 2001, p. 9-11.

PONTES, A. L. Marcas de uso em dicionários escolares brasileiros. Material didático [Notas de aula], 2012.

PONTES, A. L. Dicionário para uso escolar: o que é como se lê. Fortaleza: EdUECE, 2009.

PONTES, A. L. O dicionário na sala de aula: saberes e aplicações. In: PONTES, A. L.; COSTA, M. A. R. (org.). Ensino de língua materna na perspectiva do discurso: uma contribuição para o professor, v 2. Fortaleza: Edições Demócrito Rocha, 2008, p. 27-59.

PORTO DAPENA, J.-Á. Manual de técnica lexicográfica. Madrid: Arcos Libros S. L., 2002.

PRIBERAM. Pederastia. Dicionário Priberam de língua portuguesa (online). Priberam Informática S.A., 2013. Disponível em: https://www.priberam.pt/dlpo/pederastia. Acesso em: jan. 2018.

RAMOS, R. A. (ed. resp.). Dicionário didático de língua portuguesa. 2. ed. São Paulo: SM, 2011.

SANTOS, H. L. G. dos. Verbetes lexicográficos e Processos: uma abordagem metalexicográfica e sistêmico-funcional de dicionários escolares. 2016. $126 f$. Dissertação (mestrado acadêmico em Linguística Aplicada) - Universidade Estadual do Ceará, Centro de Humanidades, Programa de Pós-graduação em Linguística Aplicada. Fortaleza, $2016 . \quad$ Disponível em: http://www.uece.br/posla/dmdocuments/Disserta\%C3\%A7\%C3\%A3o Hugo\%20Leo nardo .pdf. Acesso em: jan. 2018.

SARAIVA, K. S. A.; OLIVEIRA, R. C. G. Saraiva jovem: dicionário da língua portuguesa ilustrado. São Paulo: Saraiva, 2010.

STREHLER, R. G. Variação e Dicionários. Linguagem em Foco, v. 04, p. 105-124, 2013. 
STREHLER, R. G. Marcas de uso nos dicionários. In: PIRES DE OLIVEIRA, A. M. P.; ISQUERDO, A. N. (orgs.). As ciências do léxico: lexicologia, lexicografia, terminologia. 2. ed. Campo Grande, MS: Ed. UFMS, 2001, p. 171-180.

WEINMANN, A. de O.; CULAU, F. V. Notas sobre o politicamente correto. Estudos e Pesquisas em Psicologia, v. 14, n. 2, p. 628-645, 2014. DOI: https://doi.org/10.12957/epp.2014.12663

WELKER, H. A. Dicionários: uma pequena introdução à lexicografia. Brasília: Thesaurus, 2004. 